\title{
Class I pentalogy of Cantrell: a rare case report
}

\author{
Bayram Ali Dorum¹, Hilal Ozkan'1, Nilgun Koksal ${ }^{1}$, Yasemin Denkboy Ongen² \\ ${ }^{1}$ Division of Neonatology, Department of Pediatrics, Uludag University School of Medicine, Bursa, Turkey \\ ${ }^{2}$ Department of Pediatrics, Uludag University School of Medicine, Bursa, Turkey
}

\begin{abstract}
Pentalogy of Cantrell is characterized by the presence of five major congenital defects involving the abdominal wall, pericardium, diaphragm, lower sternum and various cardiac abnormalities. This rare syndrome was described by Cantrell in 1958 and it has poor prognosis. We report here a case of class I Cantrell syndrome and our aim is to share difficulties experienced and review the related literature.
\end{abstract}

Keywords: Cantrell syndrome, ectopia cordis, omphalocele, ventricular diverticulum

\section{Introduction}

Cantrell syndrome is a quite rare congenital defect resulting from the defective development of the septum transversum [1]. The syndrome, which is also called the pentalogy of Cantrell, has five main components: various congenital heart defects, sternum anomalies, developmental disorders of the anterior diaphragm, pericardial anomalies, and abdominal wall defects [2]. The syndrome was firstly described by Cantrell in 1958 and it progresses lethally [3]. Although it is rarely diagnosed in the early postnatal period, this case report focuses on the difficulties encountered during management of the case.

\section{Case Presentation}

A term newborn girl delivered with cesarean section from a 28-year-old mother from her second pregnancy as the first living child was admitted to the newborn intensive care unit because of the omphalocele. Her APGAR scores were 7 and 8 at $5^{\text {th }}$ and $10^{\text {th }}$ minutes, respectively. Antenatal history revealed abdominal wall defect, supraumbilical omphalocele and ventricular septal defect (VSD) at $24^{\text {th }}$ week of the pregnancy. There was no family history suggestive of birth defects. Her birth weight was $3,620 \mathrm{~g}$ ( $50^{\text {th }}$ percentiles $)$, height $50 \mathrm{~cm}\left(50^{\text {th }}\right.$ percentiles), and head circumference $34.5 \mathrm{~cm}\left(50-90^{\text {th }}\right.$ percentiles). Physical exam revealed supraumbilical omphalocele and a neighboring pulsatile structure compatible with cardiac heart-beats (ectopia cordis) (Figure 1). Evaluation of other systems revealed no pathology. The abdominal ultrasound showed bowel loops and left lobe of the liver in the omphalocele sac, otherwise normal findings. Echocardiography showed 


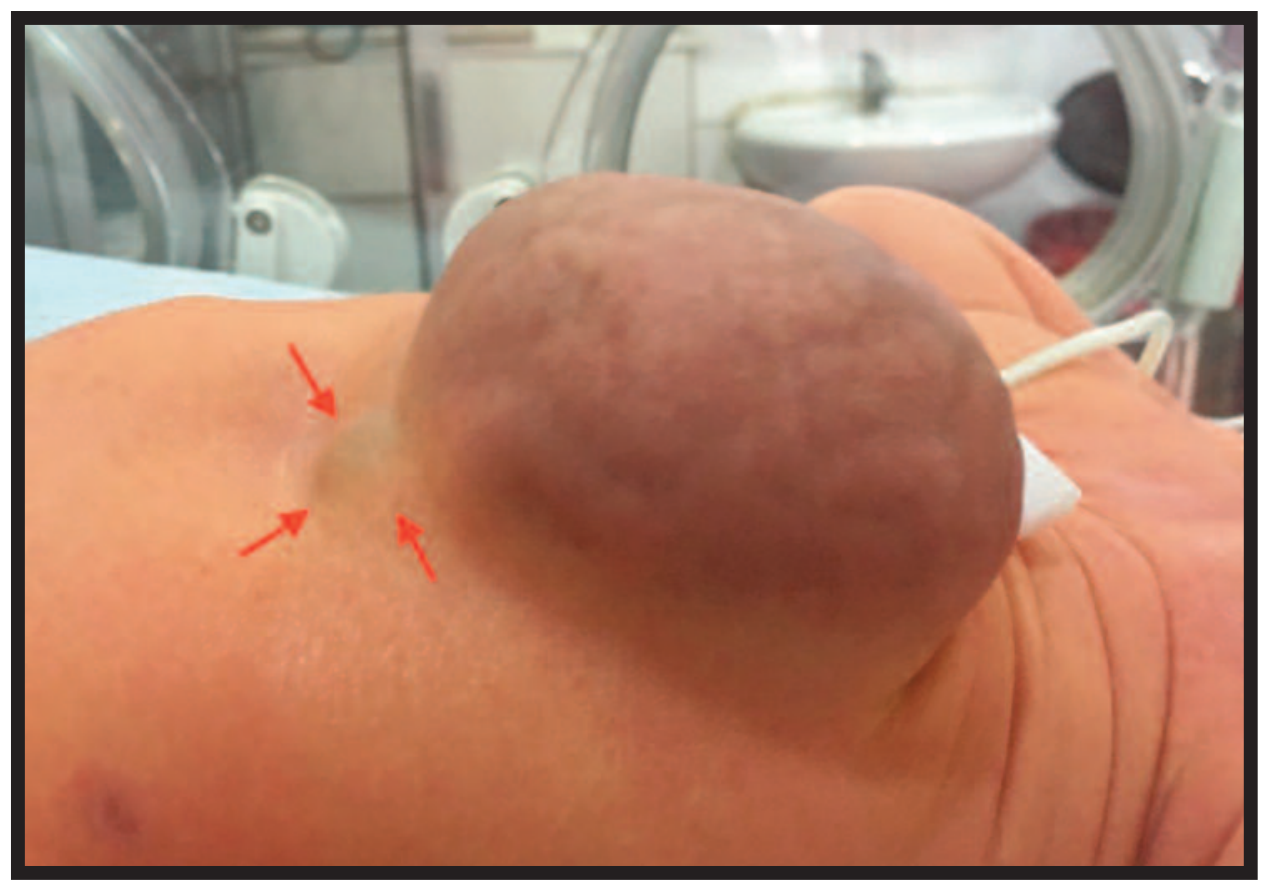

Figure 1. Preoperative photograph of omphalocele sac and ectopia cordis (red arrows)

perimembranous VSD and a diverticulum extending from the left ventricle into the abdomen adjacent the omphalocele sac. Radiograms of the skeletal system were normal. Cardiac diverticulum and omphalocele sac filled with left liver lobe and bowel loops were visualized on $\mathrm{CT}$ and $\mathrm{CT}$ angiography (Figures 2 and 3). Chromosomal analysis showed a normal female karyotype. On the 8th day of life, the patient was operated. The omphalocele sac and the diaphragmatic defect were repaired primarily and the cardiac diverticulum was excised. During the operation, it was realized that the anterior diaphragm, diaphragmatic pericardium and the inferior end of the sternum were undeveloped. With these findings, the complete

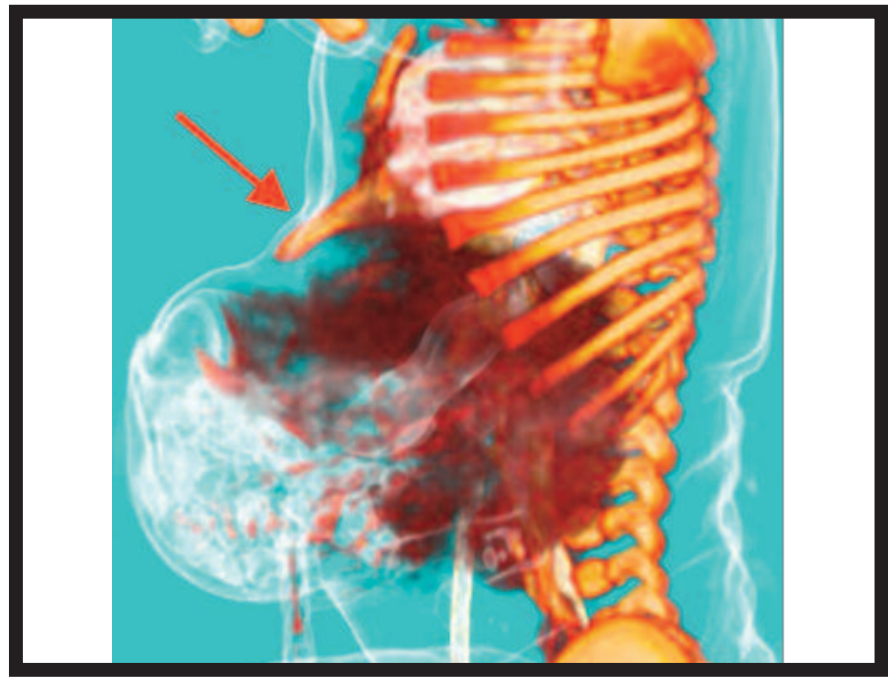

Figure 2. Volume Rendering 3D CT image (left oblique view) showing omphalocele sac and ectopia cordis (red arrow) pentalogy of Cantrell was considered. During postoperative follow-up period the patient needed 16 days of mechanical ventilation - 14 of which intubated and 2 noninvasive. On the first 5 days of this period, she was monitored with high-frequency oscillatory ventilation and was given inotropes (dobutamine 5 $\mathrm{mcg} / \mathrm{kg} /$ day). On the 12 th day after the operation, the patient was started enteral nutrition, on the $19^{\text {th }}$ day she tolerated full enteral feeding. There were not any cardiac and respiratory complications during the follow-up and the patient was discharged on the $29^{\text {th }}$ day with no need to oxygen support. The patient does not have any problems and is 5 months old at the present day.

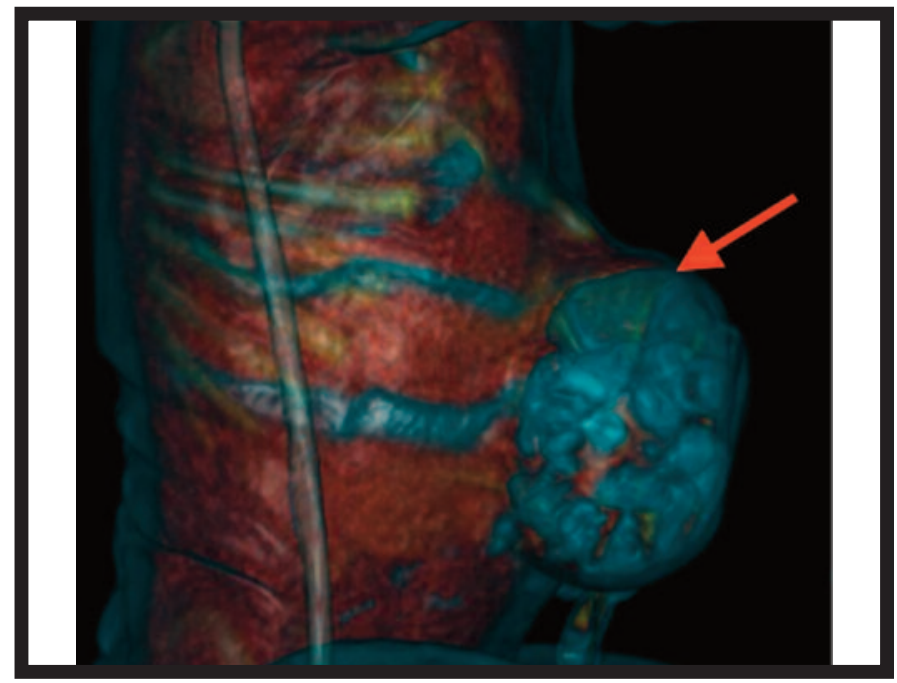

Figure 3. Volume Rendering 3D CT image (right oblique view) showing omphalocele sac and ectopia cordis (red arrow) 


\section{Discussion}

The pentalogy of Cantrell results from the ventral migration defect of the septum transversum which originates from the mesoderm on the $3^{\text {rd }}$ week of embryonic life [1]. The thoracic diaphragm, anterior abdominal wall and front bowel develop from the septum transversum. The incidence is $5.5-7.9$ per 1 million live births [1]. It is considered to be X-linked and deletion on the Xq25-26.1 locus is detected [4]. Some sporadic cases have also been reported. Steiner et al. [5] have detected duplication of the ALDH1A2 gene on the long arm of the 15 th chromosome with the chromosomal microarray analysis. Our case has normal female karyotype (46, XX) but microarray analysis could not be done.

The cardinal findings are cardiac and sternal anomalies, diaphragm and pericardium development disorders and abdominal wall defects. Toyama [6] suggested a classification for the pentalogy of Cantrell based on the expression of these five findings: definite diagnosis with all 5 defects (class I), probable diagnosis with four defects (including intracardiac and ventral wall abnormalities) (class II), and incomplete expression with varying combinations of defects including a sternal abnormality (class III). Our patient has all the five findings, and was diagnosis as class I pentalogy of Cantrell. The most important finding, which also determines the prognosis, is the cardiac anomaly. The most common ones are VSD (72-100\%) and ASD $(34-53 \%)$ [3, 4]. Our patient had VSD and diverticulum, of which the incidence is $20-32 \%$. Other reported cardiac anomalies are pulmonary stenosis, pulmonary atresia, the tetralogy of Fallot, transposition of the great arteries, dextrocardia and double outlet right ventricle $[1,4]$. The most common abdominal wall defect is omphalocele (62\%) [7]. Epigastric or umbilical hernia, and diastasis recti might also be seen [8]. Ninety-one percent of patients have ventral diaphragmatic hernia. During the operation, we detected that the anterior diaphragm and diaphragmatic pericardium were underdeveloped and the cardiac diverticulum was extending through these defects into the abdomen. Incidence of the absence of the pericardium is reported as $75 \%$ in the literature [9]. Sternum anomalies constitute bifid sternum $(26 \%)$ or the absence of the lower $2 / 3$ part of the sternum and $10 \%$ of patients do not have the xyphoid bone, like the case in our patient [9]. Besides these five cardinal anomalies, central nervous system anomalies such as cleft lip and palate, hydrocephaly, encephalocele or skeletal anomalies such as clubfoot and the absence of ulnae or radius, urinary system anomalies such as polysplenia have been reported in the publications as malformations accompanying the syndrome [10]. Our patient did not have any of these anomalies. Chromosomal anomalies such as trisomy 13 or 18 and Turner syndrome have been reported to accompany the syndrome, so a chromosomal analysis should always be done [4]. Our patient did not have any chromosomal anomalies.

Treatment is always surgical but the timing of the operation is controversial. While an early operation is suggested for abdominal and thoracic wall defects, a later time is suitable for cardiac anomalies. Thoracoabdominal ectopia cordis which is closely neighboring the omphalocele can be treated during the abdominal operation at early days. Mendaluk et al. [10] have reported discharging a patient on the $35^{\text {th }}$ day after operating the omphalocele and thoracoabdominal ectopia cordis on the $2^{\text {nd }}$ day of life. As patients with intracardiac diverticulum are at risk of complications such as rupture, tachyarrhythmia and thrombosis, early excision is recommended [8]. Our patient was operated on the $8^{\text {th }}$ day of life; diverticulum resection, diaphragm, and omphalocele sac reparations were done during the same operation by two different teams. No postoperative complication was seen.

Although general tendency is towards treating cardiac diverticulum surgically, there are some publications reporting asymptomatic patients with diverticulum. Jia and Yinbing [11] reported a case having pentalogy of Cantrell with a left ventricular diverticulum, who was asymptomatic until age 4 and operated at that age. Yang et al. [4] reported a case who had a VSD, cardiac reposition and omphalocele and operated at 3 months old. The patient had cardiac diverticulum, it was not excised and no complication was observed during the one-year follow-up [4]. In our facility, tendency is towards treating cardiac diverticula surgically.

Prognosis usually depends on the severity of the cardiac anomaly. Even under the best circumstances, the mortality rate is over $50 \%$ and patients are lost because of complications like diverticulum rupture, hypotension, bradycardia, tachyarrhythmia or heart failure [4]. De Rubens Figueroa et al. [7] have analyzed 21 patients with pentalogy of Cantrell on their retrospective observational study and reported that 17 patients died in the first 5 months and 4 cases having ectopia cordis were among them. Causes of death are septic shock, sepsis, cardiogenic shock, 
cardiac failure and organ failure [7].

During the 5 months follow-up our patient did not develop any complications and there was no cardiac dysfunction on control echocardiographies.

\section{Conclusion}

The pentalogy of Cantrell is a quite rare syndrome and most of patients do not have a high chance of survival despite proper surgical interventions and the prognosis depends mostly on the severity of cardiac anomalies. Cantrell syndrome must always be considered in patients with prenatal diagnosis of omphalocele and cardiac anomalies and chromosomal analysis should be done. Birth should be made at a medical center where pediatric surgeon teams, pediatric cardiovascular surgeons and newborn intensive care unit are present in order to increase the chances of survival.

\section{Informed consent}

Written informed consent and photography release forms were obtained from the parents of the patient for the publication of this case report.

\section{Conflict of interest}

The authors declared that there are no potential conflicts of interest with respect to the research, authorship, and/or publication of this article.

\section{References}

[1] Madzarac V, Matijevic R, Skrtic A, Duic Z, Fistonic N, Partl JZ. Pentalogy of Cantrell with unilateral kidney evisceration: a case report and review of literature. Fetal Pediatr Pathol 2016;35:43-9.

[2] Naburi H, Assenga E, Patel S, Massawe A, Manji K. Class II pentalogy of Cantrell. BMC Res Notes 2015;8:318.

[3] Timur H, Tokmak A, Bayram H, Cakar ES, Danisman N. Coincidence of incomplete pentalogy of Cantrell and meningomyelocele in a dizygotic twin pregnancy. Case Rep Obstet Gynecol 2015;2015:629561.

[4] Yang Y, Jiang Z, Ding F. One-stage surgical treatment for Cantrell syndrome without repairing the left ventricular diverticulum: a case report. Cardiol Young 2016;26:191-3.

[5] Steiner MB, Vengoechea J, Collins RT. Duplication of the ALDH1A2 gene in association with pentalogy of Cantrell: a case report. J Med Case Rep 2013;7:287.

[6] Toyama WM. Congenital defects of the anterior abdominal and review of the syndrome. Pediatrics 1972;50:778-92.

[7] de Rubens Figueroa J, Sosa Cruz EF, Diaz Garcca L, Carrasco Daza D. Cardiac malformations in patients with pentalogy of Cantrell and ectopia cordis. Rev Esp Cardiol 2011;64:615-8. [Article in Spanish]

[8] Singh N, Bera ML, Sachdev MS, Aggarwal N, Joshi R, Kohli V. Pentalogy of Cantrell with left ventricular diverticulum: a case report and review of literature. Congenit Heart Dis 2010;5:4547.

[9] Chandran S, Ari D. Pentalogy of Cantrell: an extremely rare congenital anomaly. J Clin Neonatol 2013;2:95-7.

[10] Mendaluk T, Moscicka A, Mrozinski B, Szymankiewicz M. The incomplete pentalogy of Cantrell - A case report. Pediatr Pol 2015;90:241-4.

[11] Jia H, Yinbing X. Surgical treatment of three cases of Cantrell's syndrome. J Med Coll PLA 2009;24:296-300. 